\title{
EL TRICENTENARIO DE LOPE DE VEGA EN LA CARTELERA MADRILEÑA
}

\author{
THE TERCENTENARY OF LOPE DE VEGA \\ IN THE MADRID THEATER PRODUCTIONS
}

\author{
María José ZAMORA MUÑOZ \\ Escuela Superior de Canto de Madrid \\ mariajosezamoramunoz@gmail.com
}

\begin{abstract}
Resumen: Este artículo presenta el alcance del tricentenario de Lope de Vega en la actividad teatral española de 1935 tomando la cartelera madrileña como referente para analizar su proyección pública. El elevado número de piezas representadas y el éxito de muchas de ellas muestran cómo la innovación teatral fue capaz de acercar el teatro clásico al gran público.
\end{abstract}

Palabras claves: Tricentenario de Lope de Vega. Cartelera teatral. Madrid. Historia del teatro representado.

\begin{abstract}
This article presents the scope of the tercentenary of Lope de Vega in the Spanish theatrical activity in 1935 taking the Madrid billboard as a reference to analyze its public screening. The high number of pieces represented and success of many theatrical show how innovation was able to bring classical theater to the general public.
\end{abstract}


Key Words: Tercentenary of Lope de Vega. Theater Productions. Madrid. Theater History Represented.

El 27 de agosto de 1935 se cumplía el tercer centenario de la muerte de Lope de Vega. A lo largo del año, e incluso durante los primeros meses de 1936, se sucedieron numerosos actos auspiciados por instituciones oficiales y promotores privados: desde ediciones de sus obras y estudios sobre el autor, ciclos de conferencias, actos de divulgación, recitales, paseos literarios, inauguraciones, concursos artísticos a inauguraciones e incluso el 30 de diciembre se abrió al público su casa madrileña de la calle Cervantes, número 11. El Ministerio de Instrucción Pública nombró una Junta del Tricentenario, presidida por Ramón Menéndez Pidal, para promover, coordinar y subvencionar proyectos. Con el objetivo de descentralizar los actos para que llegasen al mayor número de personas y a todo tipo de poblaciones, la Junta pidió la colaboración de las universidades para organizar juntas distritales, provinciales y locales que impulsaran su promoción y difusión entre diputaciones, ayuntamientos, academias, ateneos y organismos culturales.

Las representaciones teatrales de las obras de Lope despertaron la expectativa del público y la crítica. De hecho, la primera iniciativa partió de Antonio Machado, quien en agosto de 1934, como miembro del Consejo Nacional de Cultura, propuso a este organismo la asignación de una partida presupuestaria para culminar la creación del Teatro Nacional como el mayor homenaje posible para quien fuera el creador del teatro español.

Para entender el alcance en términos relativos que tuvieron las obras representadas para la ocasión, es necesario contextualizarlas dentro de la cartelera de aquel año. Se ha escogido para ello la de Madrid al aglutinar la mayor parte de la oferta teatral ${ }^{1}$. Aunque Barcelona también

${ }^{1}$ Para consultar la cartelera de otras localidades, remito a Romera Castillo (2011: 173184) y a las tesis de doctorado en diversos lugares de diferentes ciudades de España y fuera de ella, estudiadas en el Centro de Investigación de Semiótica Literaria, Teatral y 
contaba con una amplia oferta y un público tan numeroso como el de Madrid, la cartelera, salvo las obras en lengua catalana, solía coincidir en las dos ciudades, pues en ellas recalaban todas las compañías en gira. Los estrenos de las grandes compañías solían hacerse en Madrid o en Barcelona. Las más modestas preferían otras capitales de provincia para calibrar su acogida aunque, si se aspiraba a alcanzar una relevancia en el panorama teatral español, la compañía debía recibir los aplausos de la capital. Por otra parte, Madrid, cuyos corrales habían sido el escenario de sus más memorables triunfos, donde había transcurrido la mayor parte de su vida y donde le había llegado la muerte al que se consideraba hijo predilecto de la ciudad, fue el principal motor de la efeméride. Los datos se han consultado en Heraldo de Madrid, por su rigor y exhaustividad en la sección dedicada a la cartelera, y en el estudio de Luis M. González (1996). Este último solo recoge el teatro de las salas comerciales, sin tener en cuenta otros espacios de carácter privado o al aire libre donde se llevaron a escena, en ocasiones con gran éxito de público, algunos espectáculos organizados para conmemorar el tricentenario.

La temporada teatral empezaba en septiembre y acababa, generalmente, en junio. Para analizar, por tanto, cuáles fueron las preferencias del público en 1935, recogemos parte de la cartelera correspondiente a la temporada 1934-35 y a la de 1935-36.

\section{LA CARTELERA MADRILEÑA EN 1935}

A pesar de la proclamada crisis del teatro y la durísima competencia de los precios del cine que cada vez contaba con más adeptos, Madrid contaba con una gran oferta teatral y un buen número de compañías teatrales. El teatro seguía siendo un lugar de encuentro y de diversión para

Nuevas Tecnologías, dirigido por el profesor José Romera Castillo, que pueden verse completas en http://www2.uned.es/centro-investigacion-SELITEN@T/estudios_sobre_ teatro.html [27/05/2018]. 
buena parte de la sociedad madrileña, no exento de cierto lucimiento social para las clases más elevadas. Durante el año 1935 se representaron 393 títulos, de ellos 169 estrenos, 17 estrenos de nuevos montajes de éxitos anteriores y 207 reposiciones, según podemos observar en la siguiente tabla:

\begin{tabular}{|c|c|c|c|c|c|}
\hline \multicolumn{5}{|c|}{ Géneros Musicales } & TOTAL \\
\hline & & Estrenos & Reposiciones & $\begin{array}{l}\text { Estrenos de } \\
\text { reposiciones }\end{array}$ & \\
\hline \multirow{4}{*}{$\begin{array}{l}\text { género } \\
\text { cómico- } \\
\text { lírico en un } \\
\text { acto }\end{array}$} & juguete cómico & & 2 & & \\
\hline & vodevil lírico & & 1 & & \\
\hline & humorada lírica & & 1 & & \\
\hline & sainete lírico & 2 & 12 & & \\
\hline \multirow{2}{*}{$\begin{array}{l}\text { género } \\
\text { cómico- } \\
\text { lírico más } \\
\text { de un acto }\end{array}$} & comedia lírica & & 3 & & \\
\hline & humorada musical & & 1 & & \\
\hline zarzuela & & 16 & 62 & 1 & \\
\hline revista & & 25 & 8 & 1 & \\
\hline $\begin{array}{l}\text { género } \\
\text { flamenco }\end{array}$ & & 10 & 1 & & \\
\hline ópera & & & 6 & & \\
\hline opereta & & & 3 & & \\
\hline $\begin{array}{l}\text { drama } \\
\text { lírico }\end{array}$ & & 2 & 2 & & \\
\hline \multicolumn{2}{|c|}{ Total GÉNERo Musicales } & 55 & 102 & 2 & \\
\hline \multicolumn{5}{|c|}{ GÉneros Dramáticos } & \\
\hline \multirow{4}{*}{ comedia } & comedia & 72 & 73 & 13 & \multirow{4}{*}{180} \\
\hline & comedia extranjera & 4 & 15 & & \\
\hline & comedia poética & 3 & & & \\
\hline & TOTAL COMEDIA & 79 & 88 & 13 & \\
\hline
\end{tabular}




\begin{tabular}{|c|c|c|c|c|c|}
\hline \multirow{5}{*}{ drama } & drama & 9 & 6 & 1 & \multirow{5}{*}{24} \\
\hline & drama extranjero & 2 & 2 & 1 & \\
\hline & drama histórico & & 2 & & \\
\hline & drama vanguardista & 1 & & & \\
\hline & Total Drama & 12 & 10 & 2 & \\
\hline \multirow{3}{*}{$\begin{array}{l}\text { teatro } \\
\text { clásico }\end{array}$} & teatro siglo de oro & 15 & 4 & & \multirow{3}{*}{20} \\
\hline & teatro romántico & & 1 & & \\
\hline & Total Clásico & 15 & 5 & & \\
\hline \multicolumn{2}{|c|}{ teatro infantil } & 8 & 2 & & 10 \\
\hline & TOTAL & 169 & 207 & 17 & 393 \\
\hline
\end{tabular}

Tabla 1: Obras representadas en Madrid por géneros.

La comedia, absoluta triunfadora de la cartelera, vio estrenados 80 títulos, 13 estrenos de montaje de éxitos de otras temporadas y 88 reposiciones. El autor con más obras en cartel fue Pedro Muñoz Seca, con 25 títulos ( 9 estrenos, 16 reposiciones y 10 obras en colaboración con otros autores). Le siguen Serafín y Joaquín Álvarez Quintero, con 17 títulos (4 estrenos) y Jacinto Benavente con 10 títulos (3 estrenos). Carlos Arniches vio en escena 11 obras suyas, entre ellas 1 estreno y 2 en colaboración con Joaquín Abati. Antonio Paso, 14, con 6 estrenos y 8 en colaboración. Varios son los autores que en 1935 tienen en cartel de 5 a 8 títulos: Leandro Navarro y Pascual Guillén (8, de ellos 6 estrenos); Fernández Sevilla solo o en colaboración 6, al igual que Enrique Suárez de Deza o Luis de Vargas (1 estreno); Francisco Serrano Anguita 5 (2 estrenos) y José Estremera, siempre en colaboración con otros autores. Estos datos nos indican que los autores consagrados, auténticos protagonistas de la cartelera, gozan del favor de público y sus éxitos de temporadas anteriores no dejaron de programarse. La mayoría de los títulos se emparentan con la comedia de costumbres, de corte sainetesco, con personajes populares escritos para el lucimiento de actores y actrices; otras pertenecen al subgénero denominado astracán de personajes caricaturescos y lenguaje ingenioso, saturado de chistes fáciles. Con ellas convivía la alta comedia, de ambientación urbana 
y personajes de clase media.

Si la representación alcanzaba el rotundo éxito de las 100 representaciones, esta se organizaba en beneficio del autor o de los titulares de las compañías. La representación a beneficio es el criterio elegido para establecer cuáles fueron los mayores éxitos en 1935. Desde este punto de vista, Pedro Muñoz Seca fue el autor de mayor éxito comercial con las obras Cataplún estrenada en el Isabel por su compañía titular (260 representaciones); Marcelino fue por vino (Eslava, compañía Aurora Redondo-Valeriano León, 232); Soy un sinvergüenza (en el Teatro Isabel 185, 8 en el Maravillas por la compañía de Lupe Rivas, y 13 más en el Progreso); La plasmatoria, (Isabel, compañía titular, 150); Sola (Comedia, compañía de María Mayor-Manuel Dicenta, 109 representaciones, 5 más en el Chueca ${ }^{2}$. Antonio Quintero y Pascual Guillén alcanzaron similar éxito: Morena Clara (estrenada en el Cómico por la compañía de Carmen Díaz, 231 representaciones, 40 más en el Rialto con la compañía de Amparo Martí. La versión cinematográfica de Florián Rey estrenada al año siguiente repetirá tan sonado éxito); Oro y marfil (Fontalba, compañía Guevara-Rivelles, 118, 10 más la reposición de la compañía Amparo Martí en el Rialto); La inglesa sevillana (Teatro de la Zarzuela, compañía Irene López Heredia-Mariano Asquerino con escenografía de Manuel Fontanals, 100). De Torcuato Luca de Tena ¿Quién soy yo? (211 representaciones en el Alcázar, compañía de Rafael Rivelles), Creo en ti de los hermanos Jorge y José Cueva y Orejuela, (Lara, 150 con su compañía titular). Los hermanos Quintero, que vieron en escena 17 títulos, llegaron a las 125 representaciones con La risa, por la compañía de Carmen Díaz en el Cómico. Suárez de Deza gozó de gran éxito con los estrenos de Mamá

\footnotetext{
${ }^{2}$ Díez-Canedo, en su crítica al estreno de Sola (1968: 322), desmenuza las que él considera características del género asi: "La comedia del señor Muñoz Seca se desarrolla en los dos actos siguientes por los usuales trámites del teatro de este favorecido autor: la arbitrariedad, en reemplazo de la inventiva, y la divagación, en lugar del episodio. Diríamos también la caricatura en vez del retrato, si no tuviésemos de la caricatura el más alto concepto. No son caricaturas sus personajes, sino mamarrachos, y como tales hacen reír, cuando aciertan a despertar la risa”.
} 
Inés con 100 representaciones (Cómico, compañía Loreto Prado-Enrique Chicote), La Millona (90 en el Teatro Benavente, compañía de Benito Cebrián, más 6 reposiciones en el Pavón), Adiós muchachos (más de 70 en el Teatro Lara por la compañía de Emilio Thuiller). Fernández Sevilla y Sepúlveda llegó a las 100 con la Estudiantina (Lara, compañía titular, 14 más en su reposición en el Chueca). Por último, con 97, Memorias de un madrileño, de Jacinto Benavente, en el Lara.

Los otros grandes triunfadores de la cartelera fueron los géneros musicales. Se programaron 159 títulos, 55 de ellos estrenos. La compañía de Martínez Barrera estrenó dos operetas en el Teatro de la Zarzuela de gran éxito: Luna de Mayo, con música de Ernesto Rosillo y libreto de G. Fernández Shaw y Federico Romea (126) y Siete colores, con música de Jean Gilbert y libreto de A. Paso (96). De las 16 zarzuelas estrenadas, Me llaman la presumida, música de Francisco Alonso y libreto de F. Ramos de Castro y Anselmo Carreño, alcanzó 110 representaciones (Ideal, compañía Lírica Sagi) y La españolita con música de Jacinto Guerrero y libreto de Fernández Ardavín y Pedro Luis Valentín, llegó a las 90 (Fontalba, compañía Guerrero). Los empresarios apostaron por los éxitos consolidados para programar las reposiciones: Katiuska, La del manojo de rosas, El barberillo de Lavapiés, Los gavilanes, Doña Francisquita, La Chulapona o Luisa Fernanda.

La revista fue el género que contó, si nos ceñimos al número de representaciones, con el mayor favor del público. Prácticamente todos los estrenos sobrepasaron la barrera de las 100. Para asegurar la taquilla, los empresarios volvieron a programar sonados éxitos de la temporada anterior con el reclamo de una renovada puesta en escena. La más taquillera fue $L a$ Papirusa de A. Torrado y L. Navarro (200 en el Victoria por la compañía de Irene López Heredia-Mariano Asquerino, con escenografía de Batle y figurines de Victorina Durán, 12 más en el Teatro de la Zarzuela; el 1 de septiembre, se estrenó un nuevo montaje en el Teatro de la Comedia por la compañía de Hortensia Gelabert que alcanzó las 70 representaciones). La compañía de Celia Gámez en el Coliseum estrenó Hip-Hip Hurra de 
Joaquín Vela y E. Sierra (150), Peppina de Robert Stolz (140), Las siete en punto de L. Blanco y A. Lapena (95), en el Maravillas Los inseparables de Leandro Blanco y Alfonso Lapena (75) y la reposición Las Leandras que volvió a alcanzar el no desdeñable éxito de 75 representaciones. La compañía de Laura Pinillos estrenó Las vampiresas de J. Muñoz Román y E. González del Castillo (Romea, 150), ¡Que me la traigan! de A. Paso y E. Paso con música de Faixá y Molla (Pavón, 125), La de los ojos en blanco de E. González del Castillo y José Muñoz Román (Martín, 150 y otras 50 más con las reposiciones de otras compañías), La sota de oros de Paradas y Jiménez, con música de P. Guerrero (Pavón, 100) y La colosa del Pavón de Ramos de Castro y Francisco Mayral (75). La compañía de Margarita Carvajal optó por Mujeres de fuego de E. González del Castillo y J. Muñoz Román, con música de Francisco Alonso (Martín, 150), Las inviolables de José Silva Aramburu con música de Padilla (Maravillas, 100). La compañía de Ramón Peña con El palomo ladrón de L. Candela y S. Arjona en el Martín también alcanzó las 100.

El género flamenco, de corte cómico o dramático, se había ido implantando en la cartelera. Similar al drama rural, con sus cantes y bailes flamencos ejecutados por profesionales y sus personajes populares, pobres pero honrados, presentó en la temporada seis estrenos. En el Martín la compañía de Vedrinas con Angelillo el "Niño de Utrera" estrenó Caminitos tiene el mar (65), Los hijos de nadie (20), En España manda el sol, (14, más 65 en el Ideal) y La embriaguez de la gloria (7, más 37 en el Cervantes), todas de Ángel Custodio y Javier de Burgos. En el Price la compañía de Ramón Peña estrenó La niña de los corales (30); en el Fontalba la del Niño de Marchena Cante jondo de Pedro de Gorritz (52). El popular Pastor Poeta, seudónimo de Julián Sánchez Prieto, estrenó Consuelo la Trianera (Cervantes, 50 y 10 en el Chueca) y Antonio del Pino Los faraones del Albaicín (Cervantes, 50).

Tan solo 54 títulos se programaron fuera de la apuesta segura de los géneros cómicos y musicales. 24 títulos corresponden al drama, ya sea de autor español (18 títulos, con 9 estrenos), de autores extranjeros (6 títulos, 
3 estrenos), o dramas históricos (2 reposiciones) o incluso el calificado "drama vanguardista" Tres hombres y yo de A. Bertolucci y Ordas, puesto en escena en el Teatro Rosales al inicio de la temporada de 1935-36. E1 teatro extranjero estuvo representado con 4 dramas, 2 de ellos estrenos, bien distinto del panorama de la comedia: 19, de ellas 4 estrenos, y 3 comedias policíacas. Destacó el indiscutible éxito de Yerma de Federico García Lorca por la Compañía Xirgu-Borrás dirigida por Cipriano Rivas Cherif. Estrenada el 30 de diciembre de 1934, llegó a alcanzar las 135 representaciones en el Español, y más de 150 si sumamos las representadas en Barcelona, donde se estrenó el 17 de septiembre de 1935. Los elogios fueron unánimes tanto para el autor como para la dirección e interpretación, a excepción de la prensa conservadora que incluso cuestionó la moralidad de la obra llegando a desaconsejar la asistencia al público femenino3. También gozó de un destacado éxito Noche de calma José M. Pemán en el Teatro Fontalba con 90 representaciones.

La compañía de Carmen Díaz estrenó el 23 de enero en el teatro Cómico La Dorotea de Eduardo Marquina, drama en verso basado en la obra homónima de Lope de Vega. Con escenografía de Sigfrido Burmann y figurines de D'Hoy, los principales personajes fueron defendidos por Carmen Díaz (Dorotea), Vicente Soler (don Fernando), Esperanza Ortiz (Marfisa), Matilde Muñoz Sampedro (Gerarda) y Nicolás Navarro (don Bela). Tras las 50 representaciones en Madrid, se subió a los escenarios de Pamplona (14 de julio), Valencia (21 noviembre) y Barcelona (28 de diciembre). El particular homenaje a Lope de Vega de Marquina obtuvo buen éxito de público pero despertó entre la crítica algunas objeciones,

\footnotetext{
${ }^{3}$ Antes tales polémicas, su director, Cipriano Rivas Cherif publicó en el programa de mano del estreno el 17 de septiembre en Barcelona, la siguiente nota: "IMPORTANTE: La dirección artística se complace en advertir al público que pueda acudir torpemente al reclamo de la engañosa discusión suscitada con motivo del estreno de Yerma en Madrid, que no se trata de una de tantas comedias como se anuncian inadecuadas para señoritas; antes al contrario, de un drama cuya crudeza poética se templa precisamente en la moral, rigurosa hasta la violencia, de su sinceridad" (Vilches de Frutos y Dru Dougherty, 1992: 96).
} 
sobre todo el tercer acto. El autor, fiel a la fuente en los dos primeros, recreó el tercero, completamente de su invención, a un Lope anciano, ingresado en el convento de las Trinitarias al cuidado de su hija Sor Marcela. Allí recibe la visita de Dorotea quien implora a su antiguo amante, ahora sacerdote, el perdón por sus pecados de juventud. Algunos críticos como A. Carmona (1935) y Jorge de la Cueva (1935) estimaron que esta redención engrandecía la figura del autor. E. Diez-Canedo (1935a) o Eduardo Haro (1935) la consideraron totalmente ajena al texto original y hubo incluso quien, como es el caso de Luis Araujo-Costa (1935), la censuró por su dudosa ortodoxia católica.

Diez títulos corresponden al teatro infantil que, desde hacía algún tiempo, se programaba en los teatros en sesiones matinales o en la primera sesión de la tarde, especialmente en Navidades. Los famosos títeres de Vittorio Prodecca se despidieron de la escena madrileña en 1935 con el espectáculo Adiós a España en el Teatro de la Zarzuela. Los aplaudidos Pipo y Pipa de Salvador Bartolozzi presentaron en el María Isabel Pipo, Pipa y los Reyes Magos; el Fuencarral programó Pinchapeces en la isla encantada; la compañía de José Isbert y Milagros Leal La viudita se quiere casar en el Benavente con gran éxito, aplauso de los más pequeños que compartió La niña de nieve de Jacinto Benavente, estrenada por la compañía Xirgu-Borrás en el Teatro Español y que alcanzó la no desdeñable cifra de 48 representaciones.

\section{EL TEATRO CLÁSICO Y LOPE DE VEGA EN MADRID EN 1935}

Veinte títulos se programaron de teatro clásico y romántico como se muestra en el siguiente cuadro ${ }^{4}$ :

${ }^{4}$ María Álvarez Álvarez (2015) estudia los títulos de Lope de Vega representados durante
la II República. Deja sin reseñar El degollado fingido, La locura por la honra, La puente
del mundo, La siega, La esclava de su galán y San Isidro labrador de la TEA. Considera
San Isidro labrador de Madrid puesto en escena por la compañía Díaz Artigas-Collado
una reposición. En nuestra opinión, se trata de un estreno dado que es una refundición 


\begin{tabular}{|c|c|c|c|c|}
\hline TÍTULOS LOPE DE VEGA & $\mathbf{E}$ & $\mathbf{R}$ & COMPAÑÍA & $\begin{array}{c}\text { TEATROS/ESPACIOS } \\
\text { AL AIRE LIBRE }\end{array}$ \\
\hline El acero de Madrid & $\mathrm{x}$ & & TEA & Zarzuela \\
\hline El caballero de Olmedo & $\mathrm{x}$ & & La Barraca & Coliseum \\
\hline La corona merecida & $\mathrm{x}$ & & TEA & Zarzuela \\
\hline \multirow[t]{2}{*}{ La dama boba } & \multirow[t]{2}{*}{$\mathrm{x}$} & & \multirow[t]{2}{*}{ Xirgu-Borrás } & Español \\
\hline & & & & Chopera del Retiro \\
\hline \multirow[t]{3}{*}{ El degollado fingido } & \multirow[t]{3}{*}{$\mathrm{x}$} & & \multirow[t]{3}{*}{ José Monteagudo } & Plaza Conde Aranda \\
\hline & & & & $\begin{array}{l}\text { Avda. Raimundo } \\
\text { Fernández Villaverde }\end{array}$ \\
\hline & & & & Antigua plaza de toros \\
\hline La esclava de su galán & & $\mathrm{x}$ & Carlos M. Baena & Círculo Bellas Artes \\
\hline \multirow[t]{2}{*}{ Fuenteovejuna } & \multirow[t]{2}{*}{$\mathrm{x}$} & & \multirow[t]{2}{*}{ Xirgu-Borrás } & Español \\
\hline & & & & Chopera del Retiro \\
\hline Fuenteovejuna & & $\mathrm{x}$ & La Barraca & Coliséum \\
\hline La locura por la honra & $\mathrm{x}$ & & José Monteagudo & Plaza S. Francisco \\
\hline La moza de cántaro & $\mathrm{x}$ & & Borrás-Calvo & Español \\
\hline La niña boba & & $\mathrm{x}$ & $\begin{array}{l}\text { Guerrero-Díez de } \\
\text { Mendoza }\end{array}$ & Fontalba \\
\hline Peribáñez y el comendador de Ocaña & $\mathrm{x}$ & & Club Anfistora & Capitol \\
\hline La puente del mundo & $\mathrm{x}$ & & José Monteagudo & Plaza de la Paja \\
\hline San Isidro Labrador de Madrid & $\mathrm{x}$ & & Calvo-Díaz Artigas & Eslava \\
\hline San Isidro Labrador & $\mathrm{x}$ & & TEA & Plaza Colón \\
\hline
\end{tabular}

de José Alsina de las tres piezas de Lope de Vega dedicadas al santo, La niñez de San Isidro, La juventud de San Isidro y San Isidro, labrador de Madrid, hecha expresamente por encargo de la compañía, de la Asociación de la Crítica Dramática y Musical y del mismo Ayuntamiento de Madrid. Estas dos últimas instituciones patrocinaron la obra para su estreno en las fiestas patronales de San Isidro de aquel año. Por último, no incluye en la tabla las obras de La Barraca, aunque sí lo hace en el cuerpo del trabajo. En nuestra opinión, deberían aparecer en esa estadística dado que en ella se recogen otros grupos de teatro no profesional como Club Anfistora y la TEA. Todos ellos alcanzaron, por la calidad de sus propuestas, el reconocido éxito de crítica y público. 


\begin{tabular}{|c|c|c|c|c|}
\hline \multirow[t]{3}{*}{ La siega } & \multirow[t]{3}{*}{$\mathrm{x}$} & & \multirow[t]{3}{*}{ José Monteagudo } & Plaza Comendadoras \\
\hline & & & & $\begin{array}{l}\text { Avda. Raimundo } \\
\text { Fernández Villaverde }\end{array}$ \\
\hline & & & & Antigua plaza de toros \\
\hline El villano en su rincón & $\mathrm{x}$ & & Xirgu-Borrás & Español \\
\hline \multicolumn{5}{|l|}{ OTROS AUTORES } \\
\hline García del Castañar & & $\mathrm{x}$ & Xirgu-Borrás & Español \\
\hline El Alcalde de Zalamea & & $x$ & Borrás-Calvo & Español \\
\hline La vida es sueño & & $x$ & Borrás-Calvo & Español \\
\hline Don Juan Tenorio & & $x$ & \multicolumn{2}{|l|}{ distintas compañías } \\
\hline \multicolumn{5}{|c|}{ TOTAL } \\
\hline 20 (16 de LOPE DE VEGA) & 14 & 7 & 9 & 15 \\
\hline
\end{tabular}

Tabla 2: Teatro clásico y romántico representado en Madrid en 1935.

A pesar de que en 1935 se celebraba el Centenario del Romanticismo, elegida la fecha por coincidir con la del estreno de El Trovador de García Gutiérrez, solo se programó el ya tradicional Don Juan Tenorio. La obra elegida para el Centenario se representará el 3 abril de 1936 por el Club Anfistora en la Comedia y por la nueva compañía concesionaria del Español, formada por Enrique Borrás y Ricardo Calvo, el 20 del mismo. El teatro Español incluyó en su programación, además, tres reposiciones: la compañía Xirgu-Borrás García del Castañar de Rojas de Zorrilla y la Borrás-Calvo El Alcalde de Zalamea y La vida es sueño de Calderón. Se ha incluido la compañía aficionada Club Anfistora, el Teatro Escuela de Arte (la TEA) y La Barraca por su manifiesta calidad que corroboró su éxito y la crítica, exceptuando la promovida por los medios de la derecha tradicionalista. 


\subsection{Obras representadas de Lope de Vega por compañías de teatro profesional}

La Junta del Tricentenario decidió, una vez estudiadas las propuestas recibidas y no sin polémica, subvencionar con 60.000 pesetas a la compañía Xirgu-Borrás para la representación de Fuenteovejuna, El villano en su rincón y La dama boba, con la obligatoriedad de que todas las representaciones fuesen populares, a 2’50 pesetas la más cara; con 20.000 a la Cooperativa de Actores Reunidos para representar por provincias El castigo sin venganza y La buena guarda; con 10.000 al Club Anfistora por la representación de Peribáñez y el Comendador de Ocaña y a la TEA para que llevase por los pueblos La corona merecida y El acero de Madrid. Además, subvencionaron los festejos populares de agosto en Madrid. El director José M. Monteagudo formó una compañía para representar las piezas breves seleccionadas en algunas de las plazas más emblemáticas de la ciudad: los autos sacramentales La siega (Plaza de las Comendadoras, 25), La puente del mundo (Plaza de la Paja, 26) y La locura por la honra (San Francisco el Grande, 30) y el entremés El degollado fingido (Plaza del Conde Aranda, 24) cuya réplica por la elección de esta pieza no perteneciente al autor homenajeado no se hizo esperar (Zamora Muñoz 2015: 52-54). Ante el éxito alcanzado, se decidió repetir La siega y El degollado fingido en espacios más amplios en barrios periféricos: el 1 septiembre en la Avenida Raimundo Fernández Villaverde y el 4 en la antigua Plaza de Toros. A partir de septiembre una gira cubrió las ciudades de Zaragoza, Barcelona, Valencia, Albacete, Sevilla, Huelva, Jerez de la Frontera, Mérida, Badajoz, Salamanca y León. En colaboración con ayuntamientos, entidades culturales locales y empresarios teatrales, se representaron gratuitamente en plazas, teatros y otros espacios, como el claustro de la catedral de León donde se escenificó La siega. Según el diario La Libertad, "más de 200.000 espectadores se han identificado con el teatro de Lope y han asistido gratuitamente a sus representaciones" (Anónimo, 1935). Su director también se encargó de las adaptaciones y del 
Prólogo con el que comenzaban las representaciones, protagonizado por los mismos Quevedo, Góngora, Lope, además de un pregonero, el alcalde de la villa, damas, dueñas, capitanes y mosqueteros. A continuación entraba el carro de la farándula, reproducción de un antiguo Carro de la Muerte con el lema Una farsa de mucho exemplo, portando a la compañía entre los aplausos del público. De la escenografía se encargó Sigfrido Burmann. Construyó una sencilla embocadura con dos altos varales que sujetaban una cortina y unas rejas, único motivo ornamental que permitía su fácil adaptación a los distintos espacios. Para evitar cualquier tipo de fondo pintado, añadía algunos apliques a los muros de las casas e iglesias de las plazas, integrándolas así a la arquitectura escenográfica.

Unión Radio transmitió las representaciones populares de agosto patrocinadas por la Junta del Tricentenario: El degollado fingido desde Plaza del Conde Aranda el 24, presentada por Arturo Mori; La siega desde la Plaza de las Comendadoras el 25, con José Francés al micrófono; $L a$ puente del mundo desde la Plaza de la Paja el 26, comentada por Luis Astrana Marín; La locura por la honra desde la Plaza San Francisco el Grande el 30, con Pedro de Répide como locutor.

La compañía de Margarita Xirgu y Enrique Borrás había sido concesionaria del teatro Español desde la temporada 1930-31. Coincidiendo con la celebración del Tricentenario perdió la concesión, no sin polémica (Zamora, 2015:316-331). Con el asesoramiento literario de Américo Castro y José Fernández Montesinos, llevaron a escena Fuenteovejuna, El villano en su rincón y La dama boba, según la versión de Federico García Lorca. El director de la compañía, Rivas Cherif, contrario a las refundiciones románticas plagadas de mutilaciones, volvió a los textos originales logrando recuperar el ritmo escénico sacrificado durante décadas. Fue tal el cambio que, acogidos por la crítica como auténticos estrenos, hubo quien, incluso perteneciendo a la profesión, se sorprendió ante el desconocimiento de muchos de los versos sacrificados durante tantos años de Fuenteovejuna, a pesar de que nunca había abandonado el repertorio (Santiago de la Cruz, 1935). Estrenada el 23 de marzo, estuvo en cartel hasta el 18 de junio. 
Llegó a las 60 representaciones en Madrid, dos de ellas en la Chopera del Retiro (29 de agosto y 1 de septiembre) y gozó de enorme éxito de público y crítica. Algunas funciones se representaron a beneficio de diversos colectivos: el 23 abril la función destinó su recaudación a los huérfanos de la revolución de Asturias; el 24 del mismo, al Montepío de Empleados del Ayuntamiento; el 24 de mayo a los Comedores de Asistencia Social. En otras funciones se invitó a los miembros participantes en algunos de los congresos celebrados en Madrid, como el IV Congreso de Cooperativas de España y el II Congreso Internacional de Bibliotecas y Bibliografía (25 de abril y 22 de mayo respectivamente). El 19 de mayo, costeada por el Ayuntamiento, fue gratuita para el público madrileño. El 1 de septiembre fue patrocinada, una vez perdida la concesión, por el Centro Cultural Enciclopédico. Fuera de Madrid, el 29 de junio se representó en el Palacio de Carlos V de Granada y, unos días más tarde, en el Teatro de Verano de Jaén. El 24 de agosto se representó en la Plaza de la Libertad de Fuenteovejuna, el pueblo cordobés protagonista de la obra. En el Teatro Barcelona de la ciudad homónima, estrenada el 10 octubre, se ofrecieron 10 representaciones. El teatro Olimpia barcelonés organizó el 23 de octubre, patrocinado por el Círculo Artístico, el Ateneo Barcelonés y la Asociación del Teatro Selecto, un homenaje a Margarita Xirgu. La compañía eligió este título para mostrar su agradecimiento. Finalmente, se pudo en Valencia el 26 del mismo mes.

El escenógrafo titular de la compañía, Sigfrido Burmann, consiguió esquematizar formas y espacios apoyándose en los efectos del color de la luminotecnia diseñada por Benito Delgado y, a través de planos formados por paños y practicables, facilitar los movimientos de masas. Los figurines fueron diseñados por Victorina Durán y Miguel Xirgu, supervisados por Federico García Lorca. Los asesores musicales de la compañía, Eduardo Martínez Torner, Castro-Escudero y Jesús Bal y Gay, reconstruyeron una danza antigua con arcos para las seguidillas de Laserna del s. XVIII "Vivan muchos años los desposados" y recuperaron "Sea bienvenido el Comendadore", romance popular recogido por Salinas, una canción 
anónima del siglo XVI y “Al val de Fuenteovejuna”. De la coreografía se encargó Paloma Pardo, profesora de la TEA, y fue interpretada por sus alumnos y alumnas. La crítica alabó la interpretación de todo el elenco: Pilar Muñoz (Pascuala), Isabel Prada (Jacinta), Pedro López Lagar (Comendador), Fernando Aguirre (Mengo), Enrique Álvarez Diosdado (Frondoso), Miguel Ortiz (Rey don Fernando), Fernando Porredón y Enrique Guitart) y, especialmente, el de sus protagonistas, Margarita Xirgu y Enrique Borrás, por su gran fuerza expresiva. En La Chopera del Retiro se incorporó Amelia de la Torre. El propio Rivas Cherif tuvo que sustituir a Enrique Álvarez Diosdado en las funciones de Jaén y Fuenteovejuna por encontrase aquel enfermo. Tras abandonar Enrique Borrás la compañía a primeros en septiembre, Pedro López Lagar pasó a interpretar el papel de Alcalde.

El villano en su rincón se estrenó el 1 de junio y estuvo en cartel hasta el 23 del mismo. Fue la obra elegida por la compañía para su despedida definitiva de Madrid el 4 de septiembre. Llegó a las 45 representaciones con gran éxito de crítica, aunque esta vez no de público. De nuevo la escenografía estuvo a cargo de Sigfrido Burmann y el vestuario lo diseñó Victorina Durán. Enrique Casal y Chapí, director musical de la TEA, musicalizó dos romancillos y la "Canción aceitunera", ocupándose también de su concertación. En la coreografía colaboraron Paloma Pardo y José Jordá, ambos de la TEA. Enrique Borrás, Margarita Xirgu y Pedro López Lagar, en los papeles protagonistas, fueron muy elogiados por la crítica.

La dama boba se estrenó el 27 agosto en la Chopera del Retiro. El diario El Liberal quiso colaborar con el homenaje a Lope de Vega sumándose al patrocinio la obra. Se ofrecieron 2 representaciones a las que se añadieron 20 más en el Español. Las cinco mil sillas instaladas fueron insuficientes y muchos espectadores sin entrada rompieron el cordón formado por los guardias, admirando la obra de pie detrás de las butacas. Según Arturo Mori, entre el público se encontraba también "lo más saliente de la vida madrileña” (1935). El 10 de septiembre se representó en 
el teatro Barcelona, 1legando a las 14 representaciones. El 27 de octubre y el 7 de noviembre, a petición del público, se hicieron dos representaciones extraordinarias en función de noche alternando con Yerma. Además, subió a los escenarios del teatro Bretón de Logroño, del Arriaga de Bilbao, en Castellón y en Santander. Alabada unánimemente por la crítica, el público, por su parte, ovacionó a diario a la compañía.

Codirigida por Rivas Cherif y García Lorca, se trataba de la versión que el poeta había realizado para Eva Franco, directora de la Compañía Nacional de Teatro Argentina. Estrenada el 3 de marzo de 1934 en el Avenida de Buenos Aires, fue aclamada diariamente llegando a la cifra récord de 161 representaciones. Los cortes que introdujo Lorca en su versión tendieron a suprimir las relaciones demasiadas largas, retóricas o de carácter filosófico, así como otros versos no conseguidos, en opinión del autor, con el objetivo de alcanzar un ritmo escénico eficaz. La escenografía y los figurines de Manuel Fontanals fueron muy alabados. Para ambientar los distintos espacios construyó, inspirado en los originales corrales madrileños, una estructura de arcos a dos alturas comunicados por escaleras, con decoración de fondo a base de telas y tapices; un arco rodeado del follaje de La Chopera simulaba el jardín. Para adaptarla al tablado del Español, se cerró la estructura con un tejadillo. Se interpretó, bajo la dirección de Enrique Casal Chapí, la "Canción de los gatos" de Salinas, unas seguidillas de Barbieri sobre la letra "Pisaré yo el polvico", cantadas por los gitanos en el entremés cervantino La elección de los alcaldes de Daganzo, y dos canciones adaptadas por Federico García Lorca. De la coreografía se encargaron José Jordá e Isabel Gisbert. La crítica alabó la interpretación de todo el elenco, especialmente a Margarita Xirgu en el papel de Finea, capaz de transformarse, a la vez que recitaba, de boba a discreta.

La compañía de Enrique Borrás y Rafael Calvo, que había obtenido la nueva concesión del teatro Español, estrenó el 22 diciembre La moza de cántaro. Se trataba de una refundición con más de treinta años de Tomás Luceño. El vestuario fue diseñado por Manuel Comba. Asunción Casal 
defendió el papel de la moza junto a los titulares de la compañía.

El 30 de mayo se estrenó en el Eslava San Isidro Labrador de Madrid, una refundición de José Alsina a partir de las tres piezas La niñez de San Isidro, La juventud de San Isidro y San Isidro, labrador de Madrid. Fue producida por el Ayuntamiento en colaboración con la Asociación de la Crítica Dramática y Musical y la compañía Josefina Díaz de ArtigasManuel Collado, quienes defendieron los papeles protagonistas de San Isidro y Santa María de la Cabeza. El escenógrafo Manuel Fontanals creó unos fondos fijos y fondos que simulaban un retablo. De la música se ocupó Rafael Benedito a partir de transcripciones de la época; el coro fue dirigido por Agustín Rivas. En octubre se representó en el teatro Barcelona de la ciudad catalana.

La compañía Guerrero-Díez de Mendoza puso en escena 3 representaciones de la refundición de Manuel Bueno La niña boba en el Fontalba los días 16 y 17 de marzo. Como era de esperar, fueron sus intérpretes María Guerrero en el papel de Finea y Fernando Díaz de Mendoza en el de Laurencio.

Finalmente, la compañía Carlos M. Baena representó el 30 de mayo en el Círculo de Bellas Artes La esclava de su galán adaptada por Eduardo Marquina. Los principales intérpretes fueron Carlos Baena y Eva Seseño. La asistencia al acto estaba restringida para los miembros del Círculo de Bellas Artes. También se pudo ver en el teatro Rojas de Toledo (28 de mayo), en el Juan Bravo de Segovia (5 de junio) y en Madridejos (24 junio).

\subsection{Obras representadas de Lope de Vega por compañías de teatro no profesional}

La Barraca estrenó El caballero de Olmedo. El grupo universitario, como en todas las ediciones anteriores, participó en la Universidad Internacional de Verano de Santander. Dedicó, aquel año, parte de su programa a divulgar la obra de Lope entre el alumnado extranjero con los 
cursos "Lo español en la literatura" y "Lope de Vega y su obra" impartidos por José Fernández Montesinos y José María de Cossío, respetivamente. En las antiguas caballerizas se estrenó el 22 de agosto, esta vez dirigida por Modesto Higueras, El caballero de Olmedo. Hubo poco tiempo para los ensayos y la obra fue un fracaso a causa de los problemas técnicos surgidos por los cambios escenográficos. En la bolera de Puerto Chico el 26 de agosto se repuso Fuenteovejuna. Perdida ya toda subvención, el grupo tuvo que recurrir, por primera vez, a la venta de entradas, a precios populares, para cubrir los gastos de alojamiento y manutención. La Unión Federal de Estudiantes Hispanos (UFEH) y el Ateneo de Madrid patrocinaron en el Teatro Coliseum el programa doble Fuenteovejuna con El retablo de las maravillas los días 17 y 24 de noviembre y El caballero de Olmedo con Los dos habladores el 1 y 15 de diciembre. En las representaciones madrileñas, lograron resolver los desajustes técnicos de El caballero de Olmedo surgidos en Santander. Sin embargo, no pudieron prescindir de la concha del apuntador, elemento habitual, por otra parte, en la época, pero ajeno hasta entonces al grupo universitario. Las invitaciones fueron repartidas entre las entidades culturales y obreras. Se editaron unos cuadernillos con una selección de poesías de Lope para entregar al público que aplaudió entusiasta todas las representaciones. En directo desde el Coliseum y presentadas por José Luis González, fueron transmitidas desde Radio España el 1 de diciembre Fuenteovejuna y El retablo de las maravillas y el 8 El caballero de Olmedo y Los dos habladores.

Ambas obras fueron adaptadas por Lorca, quien también se ocupó de la música. Para Fuenteovejuna armonizó “Al val de Fuenteovejuna”, "Sea bienvenido el comendadore" y Danza de las agachadas. Las particellas instrumentales para guitarra, vihuela y laúd fueron armonizadas por Ernesto Halffter. Bajo la dirección de Julián Bautista, algunos miembros de la compañía tocaban la guitarra, la vihuela y el laúd o interpretaban la danza coreografiada por Pilar López Julvez mientras el coro cantaba. Para El caballero de Olmedo se interpretó la pieza de Antonio Cabezón que había inspirado a Lope, "Esta noche le mataron al caballero". De los 
decorados y trajes de Fuenteovejuna se encargó Alberto y José Caballero de los de El caballero de Olmedo.

El Club Teatral Anfistora dirigido por Federico García Lorca y Pura Maórtua de Ucelay estrenó el 25 de enero Peribáñez y el Comendador de Ocaña en el Cine Capitol. Se repuso el 7 de febrero, subvencionada por el Ayuntamiento de Madrid, y, unos días más tarde, en la Fundación del Amo. Los directores, asesorados por José Fernández Montesinos, se ocuparon también de la adaptación de la obra. Partieron de una recuperación arqueológica del texto y de la música como, de alguna manera, la escenografía, a la que se añadieron algunos anacronismos, como la incorporación de canciones populares, trajes actuales y recursos técnicos con el fin actualizar la obra. La escenografía de Manuel Fontanals fue muy admirada al conseguir ampliar visualmente el reducido espacio de la sala de cine. También lo fueron los trajes populares recogidos por Pura Maórtua de Ucelay en Montehermoso, Trujillo, Plasencia y La Alberca; otros los diseñó ella misma sobre modelos de Velázquez y Coello. Jesús Bal y Gay transcribió dos canciones antiguas adaptándolas a las letras de Lope: el romance "Antequera sale el moro" puesto en música en el siglo XVI por Fuentellana para el romance "Esto es casar con mujer hermosa" y la composición anónima número 74 a cuatro voces "Muchos van de amor heridos" del Cancionero de Palacio para "Cogióme a tu puerta el toro, linda casada". Lorca armonizó la canción de la boda y el "Trébole", a partir de canciones populares recogidas por él mismo. También se ocupó de la coreografía. A pesar de no ser un grupo profesional, la interpretación del elenco fue muy alabada por la crítica.

La TEA, dirigida por Cipriano Rivas Cherif, tenía previsto un ciclo de Lope que empezaría con El acero de Madrid a la que seguirían, con fecha de estreno el 27 de cada mes, La corona merecida, El maestro de danzar, la ópera La selva sin amor de cuya música, al estar perdida la original, se ocuparía Enrique Casal, El galán Castucho, San Isidro labrador, El nacimiento de Cristo, El Nuevo Mundo descubierto por Colón, Los locos de Valencia, La buena guarda, El caballero de Olmedo, los autos De los 
cantares y Maya, una selección de La viuda valenciana, El marqués de las Navas, Barlaam y Josafat y El amante de Toledo. El cierre del teatro María Guerrero en marzo por unas obras previstas inicialmente para un mes, pero que terminaron prolongándose indefinidamente ${ }^{5}$, redujo el programa a los dos primeros títulos en su sede y San Isidro Labrador en la Plaza de Colón con motivo de la Feria del Libro el 14 mayo.

El acero de Madrid se estrenó el 4 de febrero y se repuso en el teatro de la Zarzuela el 20 de junio. Se representaron, además, escenas de la obra en el Club Lyceum (20 marzo) y en la Plaza de Colón con motivo de la Feria del Libro (9 mayo). Para el 14 de noviembre de 1935 se anunció su representación en el Studio Masriera de Barcelona, en función exclusiva para socios del Teatro de Cámara, pero finalmente fue suspendida por dificultades en el traslado del grupo teatral. La dirección estuvo a cargo de Cipriano Rivas Cherif y José Franco. Enrique Casal Chapí compuso para la obra Canción madrigalesca para tres voces iguales con acompañamiento de flauta y guitarra, fechada el 26 de enero de 1935. La corona merecida se estrenó el 9 de marzo. Se pudieron ver, además, algunas escenas en el Club Lyceum (13 abril) y en la Plaza de Colón se representó la danza de las espadas. La dirección corrió a cargo de Juan Chabás y, en esta ocasión, el alumnado de la TEA compartió escenario con Carmen Moragas en el papel protagonista de doña Sol.

Con el asesoramiento literario de Américo Castro, José Fernández Montesinos y Joaquín de Entrambasaguas y musical de Eduardo Martínez Torner y José Castro Escudero, Rivas Cherif se ocupó de las adaptaciones de las piezas. El escenógrafo, Emilio Burgos, concibió para ambas un escenario único que, con ayuda de la iluminación, evocaba los distintos espacios escénicos.

\section{BALANCE}

Dieciséis títulos distintos se pudieron ver en Madrid en 1935,

${ }^{5}$ De hecho, se abrió en 1940 como Teatro Nacional de la Falange. 
incluyendo las obras representadas por el Club Anfistora, La Barraca y la TEA. Una reducida cifra si se toma como referencia las 393 obras, entre estrenos y reposiciones, del resto de géneros. Pablo Cistue de Castro (1935) se lamentaba desde ;Tararí! del gran esfuerzo intelectual y artístico realizado en el homenaje a Lope de Vega para un pueblo que seguía llenando "los teatros en los que trabajaba Rambal, con sus obras folletinescas, o en los que se representaba La Papirusa”. Sin embargo, el número es considerablemente más elevado si lo comparamos con los títulos de temporadas anteriores y con el número de coliseos y compañías que apostaron por un teatro que, frente a la comedia o los géneros musicales, contaba con escasa repercusión en la taquilla. En la siguiente tabla se recogen las tres temporadas anteriores, coincidentes con la II República y con la concesión del teatro Español a la compañía Xirgu-Borrás:

\begin{tabular}{|l|l|l|}
\hline \multicolumn{2}{|c|}{ TEMPORADA 1931-1932 } \\
\hline TÍTULOS & TEATROS & COMPAÑ́ÍA \\
\hline El alcalde de Zalamea & Fuencarral & Ricardo Calvo \\
\hline El castigo sin venganza & Fuencarral & Ricardo Calvo \\
\hline La vida es sueño & Fuencarral & Ricardo Calvo \\
\hline El alcalde de Zalamea & Español & Borrás-Adamuz \\
\hline Fuenteovejuna & Español & Borrás-Adamuz \\
\hline El gran teatro del mundo & Español & Xirgu-Borrás \\
\hline La prudencia en la mujer & Español & Xirgu-Borrás \\
\hline La serrana de la vera & Español & Xirgu-Borrás \\
\hline & TEMPORADA 1932-1933 & \\
\hline El alcalde de Zalamea & Español & Xirgu-Borrás \\
\cline { 2 - 3 } & Plaza de toros de las Ventas & \\
\hline La vida es sueño & Español & Xirgu-Borrás \\
\hline Nacimiento & Español & Xirgu-Borrás \\
\hline Retablo de las maravillas & Español & La Barraca \\
\hline La cueva de Salamanca & Español & La Barraca \\
\hline La vida es sueño & Español & La Barraca \\
\hline Los dos habladores & Español & La Barraca \\
\hline
\end{tabular}




\begin{tabular}{|l|l|l|}
\hline \multicolumn{3}{|c|}{ TEMPORADA 1933-1934 } \\
\hline El alcalde de Zalamea & Español & Xirgu-Borrás \\
\hline El caballero de Olmedo & Español & Meliá-Cibrián \\
\hline \multicolumn{3}{|c|}{ TOTAL } \\
\hline $\mathbf{1 2}$ & $\mathbf{3}$ & $\mathbf{5}$ \\
\hline
\end{tabular}

Tabla 4: teatro clásico representado en Madrid en las temporadas 1931-32, 1932-33 y 1933-34.

En la temporada de 1931/32 tres compañías representaron 7 títulos: la de Ricardo Calvo subió al escenario del teatro Fuencarral El alcalde Zalamea, El castigo sin venganza y La vida es sueño. El resto de las producciones, también las de las dos temporadas posteriores, se representaron en el teatro Español cuya concesión obligaba a su programación. En esta temporada, la compañía de Enrique Borrás-Ana Adamuz programó también La vida es sueño y Fuenteovejuna; la nueva concesionaria del Español, Xirgu-Borrás, El gran teatro del mundo, La prudencia en la mujer y La serrana de la Vera. En la temporada siguiente, 1932/33, se programaron El alcalde de Zalamea, La vida es sueño, El gran teatro del mundo y hemos incluido Nacimiento, una recopilación de fragmentos de Los pastores de Belén de Lope de Vega, del Auto de los Reyes de Juan del Encina y otros textos de su Cancionero, un diálogo de fray Antonio de Montesinos, villancicos, bailes y tonadillas, cuyo colofón lo puso, según los programas, un "nuevo Evangelio apócrifo" del propio Rivas titulado El aprendiz de carpintero. Además, en el mismo coliseo, se pudieron ver los entremeses de Cervantes Retablo de las maravillas, La cueva de Salamanca y Los dos habladores y el auto sacramental La vida es sueño, todos ellos por el grupo universitario dirigido por Federico García Lorca. En la temporada 1933/34, la compañía titular presentó El alcalde Zalamea y la de Pepita Melía-Benito Cibrián El caballero de Olmedo. Vistos los datos, solo se atrevieron con el repertorio clásico cinco compañías que representaron en dos coliseos, al que habría que sumar la plaza de toros de Las Ventas en la que el 14 de abril de 1934, en las fiestas 
conmemorativas del tercer aniversario de la II República y por encargo del ministro de Instrucción Pública, se representó El alcalde de Zalamea. La pretensión de que fuera un espectáculo popular se cumplió con creces y el público llenó la plaza. Las entradas se ofrecieron a un precio reducido, entre 50 céntimos y 3,50 pesetas, asequible a la mayor parte del público dado que las localidades más económicas de los teatros costaban tres pesetas.

En 1935, para celebrar el tricentenario de Lope de Vega, se implicaron nueve compañías. Fueran o no profesionales, todas se esforzaron en presentar estrenos al público madrileño: cuatro la formada para la ocasión por José Monteagudo, tres la Xirgu-Borrás, dos la TEA, una BorrásCalvo, Calvo-Artigas y Club Anfistora. La Barraca presentó un estreno y repuso su mayor éxito: Fuenteovejuna. Las compañías de Guerreo-Díaz de Mendoza y Carlos Baena no apostaron con novedades y ambas repusieron dos piezas de su repertorio. También los espacios se multiplicaron: siete coliseos se unieron a la celebración (Español, Zarzuela, Fontalba, Eslava, Capitol, Coliséum y el teatro del Círculo de Bellas Artes) a los que habría que sumar ocho espacios al aire libre (Chopera del Retiro, las plazas del Conde de Aranda, de las Comendadoras, de San Francisco el Grande, de la Paja, de Colón, la antigua plaza de toros y la avenida de Raimundo Fernández Villaverde) que el público madrileño llenó entusiasmado.

Los títulos recorrieron todos los géneros: la comedia con El acero de Madrid, La dama boba o La niña boba, La esclava de su galán, La moza de cántaro y El villano en su rincón; el drama con El caballero de Olmedo, La corona merecida, Fuenteovejuna y Peribáñez y el comendador de Ocaña; el entremés con El degollado fingido (aunque no pertenece al autor); los autos sacramentales con San Isidro, La locura por la honra La puente del mundo, La siega y la refundición de José Alsina San Isidro Labrador, basada en las tres piezas teatrales del autor sobre el santo. El público llenó los teatros (quizá la excepción fue La villana en su rincón, que, a pesar del reconocimiento unánime en esta ocasión de la crítica, no logró llenar el éxito recíproco del público) y abarrotó las plazas en 
las representaciones populares de agosto. Con la trasmisión de cinco de los títulos del año de Lope por Unión Radio, podemos considerar que el alcance fue aún mayor.

A propósito del tricentenario, Fernández Montesinos (1935:24) había afirmado que la escasa programación del teatro clásico se debía no tanto a la dificultad textual como a una concepción escénica obsoleta en el innovador panorama de la dramaturgia europea. Aunque esto afectaba a todo el teatro español, era más alarmante en el caso del repertorio clásico, en cuya puesta en escena seguía prevaleciendo el modelo dramático heredado del Romanticismo. Las contadas compañías que se atrevían a incluir teatro clásico en su repertorio limitaban su presencia a unos pocos y significativos títulos. Además, su organización jerárquica y la falta de escuelas de formación perjudicaban el trabajo actoral de conjunto. Con todo, el principal problema radicaba en la falta de dirección escénica, oficio que casi siempre ejercía el primer actor. Mientras en Europa nuestro repertorio clásico inspiraba algunas de las más notables innovaciones en la dramaturgia de la época, adaptando los adelantos de la escenografía al ingenio de nuestros clásicos, en España las compañías seguían empleando refundiciones de los textos originales para aminorar costes (Díez-Canedo, 1928: 5). La concepción de la escena que presidía su actividad, derivada del empleo del telón historicista que se había introducido el siglo anterior, había tenido como consecuencia la mutilación de los textos originales con el objetivo de simplificar la multiplicidad de espacios de nuestro teatro clásico y, como consecuencia, la alteración de su ritmo escénico. Una moderna dirección teatral, en opinión de Díez-Canedo (1935c), debía partir del original y adaptarlo al propio criterio de dirección escénica. En este sentido, Rivas Cherif y García Lorca solicitaron el asesoramiento de estudiosos vinculados al Centro de Estudios Históricos, como Ramón Menéndez Pidal, Américo Castro, o Fernández Montesinos. Rivas Cherif volvió a los originales con el objetivo de recuperar su dinamismo escénico. García Lorca, por su parte, abordó el texto en función del receptor: para un público selecto, como el del Club Anfistora, se decantó por la 
reconstrucción arqueológica, con algún anacronismo para conectar con la sensibilidad del momento; para el popular, la actualización, suprimiendo versos e incluso escenas sin interés por su exceso de duración, por tratarse de versos no conseguidos o por su dificultad. También tornó al original José María Monteagudo. Solo en cinco ocasiones en el año del tricentenario se retomaron las refundiciones. Dos de ellas, El caballero de Olmedo de Julio de Hoyos y San Isidro Labrador de José Alsina, se hicieron expresamente para el tricentenario. La compañía de Guerrero-Díez de Mendoza, repuso La niña boba que José Crespo había escrito para María Guerrero en 1884 y la nueva compañía concesionaria del Español la que hiciera Tomás Luceño en 1903 de La moza de cántaro, rompiendo así el proceso de renovación emprendido por Margarita Xirgu y Cipriano Rivas Cherif.

La falta de medios técnicos ya presentes en los principales teatros europeos, como el escenario giratorio, obligaba a buscar alternativas a los más innovadores escenógrafos que se encargaron de la escena: Sigfrido Burmann, Manuel Fontanals y Emilio Burgos. Lograron con sus escenarios sintéticos y el diseño de la luminotecnia adaptarse tanto a la multiplicidad de escenarios como al movimiento de masas. Contribuyó a ello el diseño del vestuario, destacando los trabajos del propio Fontanals, Victorina Durán y Pura Maórtua de Ucelay. Al efecto plástico del conjunto contribuyeron la música y la coreografía. Como en el caso anterior, Rivas Cherif y Lorca buscaron el asesoramiento de Jesús Bal y Gay, Eduardo Martínez Torner y José Castro Escudero, del Centro de Estudios Históricos. Las partes coreografiadas y cantadas fueron las que más conectaron con el público popular. En este sentido, destacó también la labor de Lorca, quien, también músico, armonizó canciones populares, algunas recuperadas en sus viajes por los pueblos, incorporándolas eficazmente a la acción. Por otra parte, ambos directores también huyeron de la grandilocuencia en la interpretación del verso clásico y, además, consiguieron un trabajo de conjunto incluso contando con figuras tan carismáticas como Margarita Xirgu o Enrique Borrás. Lorca, por su parte, apostó por una compañía no jerarquizada y demostró con La Barraca y el Club Anfistora que era 
posible liberarse de los férreos roles de las compañías al uso.

Si exceptuamos la crítica de corte ideológico de la derecha tradicionalista, el éxito de crítica y público de todos ellos fue unánime. El considerable aumento de títulos programados para la celebración del tricentenario de Lope de Vega y su excelente acogida de crítica y público, culminó el proceso de modernización de la puesta en escena del teatro clásico en la que venían trabajando sus principales protagonistas, especialmente Margarita Xirgu, Cipriano Rivas Cherif y Federico García Lorca. Demostraron que era posible que el teatro clásico gozara del aplauso del gran público.

\section{REFERENCIAS BIBLIOGRÁFICAS}

ÁlVAREZ ÁlVAREZ, M. (2015). “Clásicos y vanguardia: el teatro de Lope durante la II República”. En El patrimonio del teatro clásico español: actualidad y perspectivas. Homenaje a Francisco Ruiz Ramón, G. Vega García-Luengos, H. Urzáiz Tortajada y P. Conde Parrado (eds.), 223-231. Valladolid: Universidad de ValladolidAyuntamiento de Olmedo-TC/12.

ANÓNIMO (1935). “José María Monteagudo, excepcional director de escena, da a conocer en varias ciudades los autos de Lope". $L a$ Libertad, 4, 2 de noviembre.

ARAUJO COSTA, L. (1934). "Veladas teatrales. Reposición de la comedia El caballero de Olmedo". La Época, 3, 19 de octubre. (1935). "Veladas teatrales". La Época, 3, 24 de enero.

CARMONA, A. (1935). "Informaciones teatrales. En Madrid, Cómico: La Dorotea". ABC, 35, 24 de enero.

CISTUE DE CASTRO, P. (1935, 10 octubre). “¡Pobre Lope de Vega!”. ¡Tararí!, 30, 10 de octubre.

CRUZ, S. de la (1935). "Balance y experiencia de la temporada teatral". Heraldo de Madrid, 7, 21 de junio, 
CUEVA, J. de la (1935). "Teatralias. Cómico: La Dorotea". El Siglo Futuro, 4, 24 de enero.

DÍEZ-CANEDO, E. (1928). "Teatro Nacional, teatro de repertorio". El Sol, 5, 5 de mayo.

(1934). "Información Teatral. Por aquello de que el pasado vuelve, ayer reaparición en distintos teatros de Madrid Lope de Vega, Pastora Imperio y Miguel Fleta". La Voz, 3, 19 de octubre.

(1935a). "Información Teatral. Con el estreno de La Dorotea empezó anoche a todo honor el año de Lope. En el Cómico. $L a$ Dorotea de Marquina". La Voz, 3, 24 de enero.

(1935b). "Marcelino y los posos de vino". La Voz, 4, 21 de noviembre.

(1935c). "Teatro. Los clásicos y sus adaptaciones". El Sol, 12, 1 de noviembre.

(1968). Artículos de crítica teatral. El teatro español de 1914 a 1936. Méjico: Joaquín Mortiz.

FERNÁNDEZ MONTESINOS, J. (1935). "Conmemoraciones. Centenario de Lope de Vega 1635-1935”. En Almanaque literario 1935, 24-29. Madrid: Plutarco.

GONZÁLEZ, L. M. (1996). “La escena madrileña durante la II República (1931-1939)". Teatro (revista de estudios teatrales) 9 y 10 (monográfico).

HARO, E. (1935). “Anoche se estrenó en el Cómico La Dorotea, comedia en verso, en tres jornadas de Eduardo Marquina, inspirada en $\mathrm{La}$ Dorotea, comedia en prosa de Lope de Vega". La Libertad, 4, 24 de enero,.

MORI, A. (1935). "La dama boba en el Retiro. Miles de espectadores presenciaron la función organizada por El Liberal". El Liberal, 3-4, 28 de agosto.

OLMEDILLA, J. G. (1934). “Un buen homenaje a Lope de Vega. En el Español la compañía Meliá-Cibrián, representan dignamente $E l$ caballero de Olmedo". Heraldo de Madrid, 4, 19 de octubre. 
RIVAS CHERIF, C. (1992). Cómo hacer teatro. Apuntes de orientación profesional en las artes y oficios del teatro español. Valencia: PreTextos.

ROMERA CASTILLO, José (2011). “Obras de Lope de Vega en algunas carteleras de provincias españolas (1900-1936)". En su obra, Pautas para la investigación del teatro español y sus puestas en escena, 173-184. Madrid: UNED.

VILCHES DE FRUTO M. F. y DOUGHERTY, D. (1992). Los estrenos teatrales de Federico García Lorca (1920-1945). Madrid: Tabapress-Fundación Federico García Lorca.

Z. (1935). "La estudiantina conmemora a Lope. Una representación de Fuenteovejuna al aire libre”. El Mercantil Valenciano, 4, 28 de agosto.

ZAMORA MUÑOZ, M. J. (2016). "Actividad editorial en torno al tricentenario de Lope de Vega". Anuario Lope de Vega. Texto, literatura, cultura XXII, 310-343 (también en http://dx.doi. org/10.5565/rev/anuariolopedevega.160 [20/05/2018]). (2015). El tricentenario de Lope de Vega. Una conmemoración cultural en la España de 1935. Tesis de doctorado: URJC.

Recibido el 14 de marzo de 2018.

Aceptado el 11 de mayo de 2018. 
